\title{
The Role of EMT Modulators in Hematopoiesis and Leukemic Transformation
}

\author{
Goossens Steven and Haigh J. Jody \\ $V I B$ and Ghent University \\ Belgium
}

\section{Introduction}

Mature blood cells arise from hematopoietic stem cells (HSCs) capable of generating every hematopoietic cell type; including the various lymphoid and myeloid lineages. To maintain the steady state levels of hematopoietic cells in the circulation, each HSC has the capacity to generate large numbers of mature cells daily via various multi- and oligopotent lineagecommitted progenitors (Kondo et al., 2003; Orkin, 2000). Finely tuned self-renewal and differentiation programs, controlled by essential transcriptional regulatory networks (Miranda-Saavedra \& Gottgens, 2008), determine the HSC and progenitor pool sizes in adults. These regulatory networks include both positive and negative transcriptional regulators that control lineage specific gene expression and ensure normal hematopoietic cell differentiation. Deregulation of these transcriptional networks caused by aberrant upstream signalling, point mutations as well as chromosomal translocations of key transcriptional regulators particularly within the HSC compartment (Bonnet \& Dick, 1997) can lead to various blood related disorders including anemia and hematological malignancies or leukemia.

The origins of HSCs during the development of a mammalian embryo are only beginning to be understood. Tracing of the true stem cells via marker analysis is difficult and the 'gold standard' for identifying these cells is based on their ability to reconstitute lethally irradiated hosts over a long term. Various transplantation studies in the mouse (Dzierzak \& Medvinsky, 2008) have revealed that HSCs arise in a complex developmental process during which multipotent progenitors sequentially migrate to several anatomical sites (Dzierzak \& Speck, 2008; Orkin \& Zon, 2008), including the yolk sac, the aortagonadomesonephros (AGM) region, placenta, fetal liver and finally the bone marrow in the adult (Palis et al., 2001). Lately, it is thought that the first definitive adult-type of HSCs are generated in the AGM region at embryonic day (E) 10.5 in the mouse (de Bruijn et al., 2002). It was demonstrated through fate mapping that the first HSCs arise as part of the hematopoietic progenitor clusters that emerge from the hemogenic endothelium and subendothelial layers at the ventral part of the dorsal aorta and in the vitelline artery (Rybtsov et al., 2011; Yokomizo et al., 2011). These small cell clusters of hematopoietic progenitors are closely associated with the endothelium and originate from vascular remodelling and extravascular budding (Boisset et al., 2010; Robin et al., 2011; Zovein et al., 2010). This involves changes in endothelial cell shape and loss of cellular adhesion that have 
been likened to the changes in cell adhesion that epithelial cells undergo during epithelial to mesenchymal transition (EMT). EMT encompasses a series of events in which wellpolarized epithelial cells round up in shape, lose their cell contacts and acquire the motile, migratory properties of mesenchymal cells (Greenburg \& Hay, 1982). EMT is essential for many developmental processes including mesoderm formation during gastrulation and neural crest delamination and migration (Kalluri \& Weinberg, 2009; Thiery et al., 2009). Similar EMT-like changes in cellular morphology can be observed during tumor progression and allow tumor cells to acquire the capacity to invade into the surrounding tissue and ultimately metastasize to a distant site (Berx et al., 2007). Subsequent tissue colonization occurs via a reverse transitional mechanism, called mesenchymal to epithelial transition (MET) (Kalluri, 2009). Significant cross talk and interactions between members of the Snai family and Zeb family of transcription factors have been documented to be involved in the regulation of these EMT/MET processes (Thiery \& Sleeman, 2006). More recently, it has been suggested that the expression of the EMT regulators are also involved in the formation/acquisition of (cancer) stem cell properties (Gupta et al., 2009). In addition to their roles in epithelial/mesenchymal biology there is accumulating evidence that these EMT inducers may be involved in several aspects of hematopoietic differentiation and hematological malignancies that is the main focus of this chapter and are reviewed below.

\section{EMT regulators of the Snai family}

Members of Snai family encode for transcription factors with a common structural organization consisting of a highly conserved C-terminal region with four to six $\mathrm{C}_{2} \mathrm{H}_{2}$ zincfingers (Knight \& Shimeld, 2001) and a more divergent N-terminal region (Fig. 1). This zincfinger domain serves as a sequence-specific DNA binding domain that recognizes consensus E2-box type elements C/A(CAGGTG) (Batlle et al., 2000; Cano et al., 2000; Mauhin et al., 1993). All vertebrate Snai family members share as well an evolutionary conserved 7-9 AA N-terminus, the SNAG (Snail/Gfi) domain (Grimes et al., 1996). This domain was originally identified as a repressor domain in the zinc-finger protein Gfil that acts as a molecular hook to recruit co-regulators and/or demethylases and is essential for their Snai transcriptional repressive function (Lin et al., 2010).

Snail (also known as Snai1, Sna, Snah, Slugh2, Snail1.) represents the founding member of the superfamily (Manzanares et al., 2001; Nieto, 2002) and was first described in Drosophila melanogaster (Grau et al., 1984). In mammals, besides Snail two other Snail family members were identified Slug (aka Snai2, Slugh1, Slugh, Snail2) and Smuc (aka Snai3, Zfp293, Znf293). Snail and Slug are the best characterized and have been implicated in the formation of the mesoderm (Boulay et al., 1987; Sefton et al., 1998) and neural crest cell migration (del Barrio \& Nieto, 2002; LaBonne \& Bronner-Fraser, 2000) as well as with the loss of epithelial features associated with the acquisition of a fibroblast-like motile and invasive phenotype of tumor cells. Induced expression of Snail or Slug in various epithelial cancer cell lines either by FGF, Wnt, Notch or TGF $\beta$ administration (De Craene et al., 2005) or directly via ectopic expression of the repressors is sufficient to adopt a more mesenchymal morphology (Cano et al., 2000). This phenotypic switch is characterized by the downregulation of a number of epithelial marker genes (E-cadherin, desmoplakin, Muc-1, cytokeratin-18) (Batlle et al., 2000; Cano et al., 2000) and the induction of various mesenchymal marker genes (vimentin, fibronectin) (Cano et al., 2000), which can vary dependent on the cellular context. Several 
lines of evidence indicated that Snail family members not only regulate cellular adhesion and motility or invasion but as well can bind and regulate genes that participate in other processes (Wu Y. \& Zhou, 2010) like proliferation (CyclinD1) (Liu J. et al. 2010), cell survival/apoptosis (BID, caspase-6) (Kajita et al., 2004), inflammation (Lyons et al., 2008; Yang \& Wolf, 2009) and angiogenesis (Gill et al. 2011).

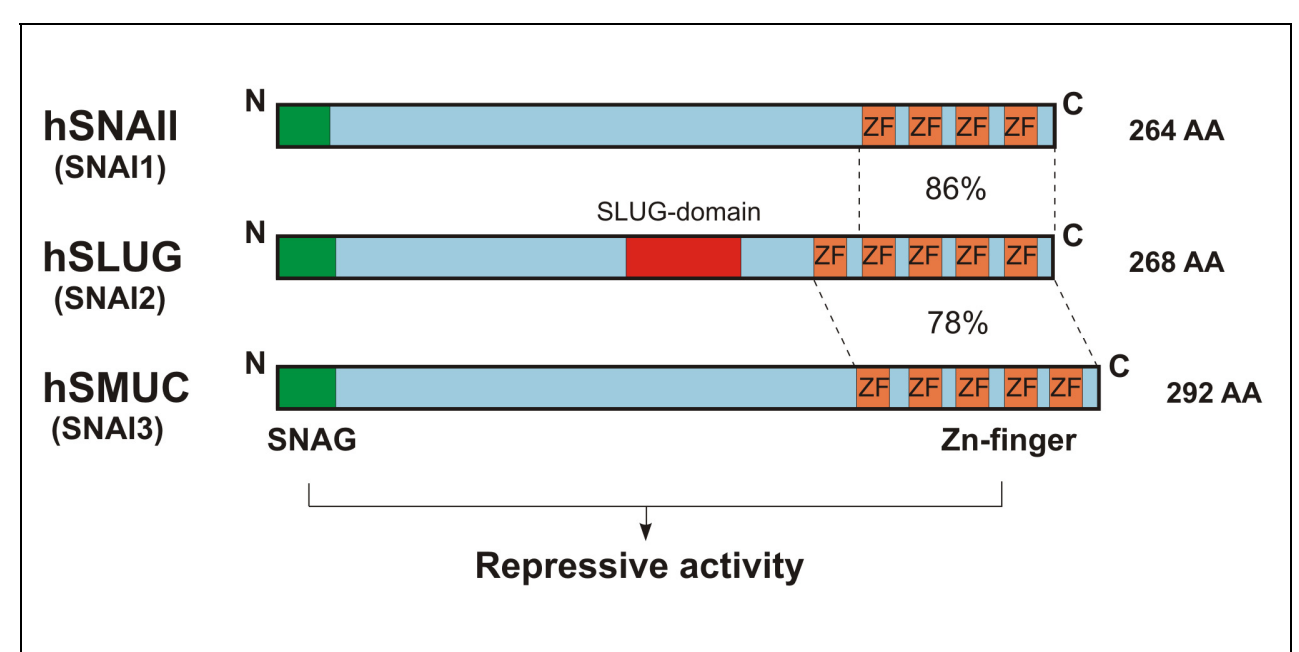

Fig. 1. Schematic diagram of conserved functional domains of the three members of the Snai family of transcription factors. All members contain an N-terminal SNAG domain and a Cterminal zinc-finger (ZF) domain. The central SLUG-domain is unique for Slug (Figure based on Cobaleda et al., 2007)

Besides this, Snai gain-of-function is correlated with the acquisition of (cancer) stem cell properties (Gupta et al., 2009). Studies of various neoplastic tissues have demonstrated the existence of cancer stem cells (CSC) or tumor-initiating-cells with self-renewal capacity that exhibit an ability to induce new tumors when transplated into nude and/or syngeneic mouse strains (Schatton et al., 2009). The existence of CSCs was initially discovered in leukemia samples (Bonnet \& Dick, 1997), but subsequently they have been identified in various solid tumor types as well (Al-Hajj et al., 2003; Ricci-Vitiani et al., 2007; Singh et al., 2004). The origin of these stem cells is until now unclear but compelling results from Mani and colleagues (Mani et al., 2008) now link EMT processes with the formation of CSCs. Ectopic expression of Snail in an immortalized human mammary epithelial cell line resulted in the acquisition of mesenchymal traits, expression of stem cell markers and enhanced capacity to form mammospheres, a property previously and exclusively associated with mammary epithelial stem cells. For now it is unclear whether this is restricted to cancer stem cells of an epithelial origin or can be generalized to all (cancer) stem cells. Somewhat contradictory to this, is the recent findings that suppression of EMT inducers and the expression of E-cadherin is one of the first essential steps during the reprogramming of fibroblasts for the generating induced pluripotent stem cells (Li et al., 2010; Redmer et al., 2011; Wang et al., 2010). This may reflect the fact that stemness properties and totipotency are not equivalent and may be controlled by divergent molecular mechanisms. 
Recently, the in vivo functions of Snail and Slug could be further analyzed by the generation of novel gain/loss-of-function mouse models. Here we shall focus more on the hematopoietic phenotypes observed in these mouse models.

\subsection{Slug is an important downstream mediator of SCF/cKit signaling and plays pivotal roles in stress-induced hematopoietic stem/progenitor cell survival and self-renewal}

The first evidence of an important role for Slug in hematopoiesis and leukemia came from study by Inukai et al. (1999) in which Slug was identified as a downstream target of the E2A-HLF oncogene in leukemic B-cells. The E2A-HLF fusion gene transforms human pro-B lymphocytes by interfering with the apoptotic signaling pathway at an early step. Moreover, Slug expression in IL3-dependent Baf-3 cells prolonged the survival of these cells significantly after deprivation of the cytokine. These initial data suggested a pivotal role for Slug in the cell survival pathway of lymphocyte progenitor cells and possibly as well in other hematopoietic progenitors, based on its expression profile. Endogenous Slug is normally expressed in both long- and short-term repopulating HSCs and in committed progenitors of the myeloid lineage but not in differentiated myeloid cells or pro-B or pro-T cells. Its role in other lineages was further investigated in vivo by the generation of Slug deficient mice. Mice lacking Slug survive and are fertile, but display postnatal growth retardation phenotypes (Inoue et al., 2002). Upon loss of Slug, normal circulating blood cell counts were observed but the number of hematopoietic colony-forming progenitors in the bone marrow and spleen were significantly (2-4-fold) increased. This suggested that in the absence of Slug, hematopoietic progenitor pools must expand to maintain normal levels of differentiated blood cells in the circulation. In addition, Slug deficient mice are more radiosensitive; these mice not only died earlier upon $\gamma$-irradiation, but as well showed accentuated decreases in peripheral blood cell counts and marked increases in apoptotic (TUNEL+) bone marrow progenitors cells compared to their control littermates. These data implicated an important role for Slug in protecting hematopoietic progenitor cells from apoptosis after DNA damage (Inoue et al., 2002). By crossing the Slug knockout mice with various other mouse models it was demonstrated that Slug directly represses the proapoptotic factor Puma and in this way is able to antagonize the p53-mediated upregulation of Puma in $\gamma$-irradiated myeloid progenitor cells, allowing them to survive (Wu W.S. et al., 2005). All together these data suggest that Slug governs a pivotal checkpoint that controls cell survival/apoptosis decisions upon exposure to genotoxic stress.

The role of Slug in the regulation of the bone marrow stem cell compartment was further investigated under both normal steady-state and stress conditions via competitive repopulating assays and serial bone marrow transplants (Sun et al., 2010). Under normal conditions, Slug deficiency seems to have no effect on proliferation or differentiation of HSC or progenitors. However, if transplanted, Slug null HSCs demonstated increased repopulating potential that was not a result of altered differentiation nor homing ability, suggesting Slug deficiency alters HSC self-renewal. Indeed this was confirmed under the stress conditions of serial bone marrow transplantation. Consistently, 5-FU treatment of Slug knockout mice showed an expansion of the Lin-Sca1+ cell population, not by changing their cell survival capacity but by increasing their proliferation rates (Sun et al., 2010).

More detailed analysis of Slug deficient mice revealed macrocytic anemia as well as pigmentation deficiency and gonadal defects (Perez-Losada et al., 2002). These phenotypes 
are very similar to the defects reported in the white-spotting $(\mathrm{W})$ and Steel $(\mathrm{Sl})$ mutant mice with mutations in the c-Kit receptor (Chabot et al., 1988; Geissler et al., 1988) and its Stem Cell Factor (SCF) ligand (Copeland et al., 1990; Huang et al., 1990; Zsebo et al., 1990). The $\mathrm{SCF} / \mathrm{c}-\mathrm{Kit}$ signaling pathway has pleiotrophic functions in hematopoiesis and beyond. The primary function of SCF/c-Kit in early hematopoiesis seems to induce the growth of quiescent progenitor/stem cells through synergistic interactions with other early-acting cytokines (Migliaccio et al., 1991; Williams N. et al., 1992). Ample evidence indicates that in the absence of other cytokines, SCF selectively promotes viability rather than proliferation of primitive murine progenitor cells (Fleming et al., 1993) and confirms previous findings of Slug playing a role in both cell cycle/proliferation and cell survival/apoptosis. Next to its role in hematopoiesis, SCF/c-Kit signaling has been implicated in the development/migration of melanocytes (Nishikawa et al., 1991). In human piebaldism patients, c-Kit signaling has been demonstrated to be involved in congenital depigmented patches and poliosis, (Giebel \& Spritz, 1991). Interestingly in some piebaldism patients, also heterozygous SLUG deletions could be detected, providing further genetic evidence that Slug may play crucial roles in the SCF/c-Kit signaling pathway (Sanchez-Martin et al., 2003). The importance of Slug as a putative downstream mediator of c-Kit signaling was further tested by means of a complementation study in which transduction with TAT-Slug protein was sufficient to rescue the radio-sensitivity of c-Kit deficient mice. Taken together these data clearly demonstrate that Slug is an important mediator downstream of c-Kit receptor activation (Perez-Losada et al., 2003).

The observed macrocytic anemia observed in the Slug mutant mice resemble in some ways human congenital anemias such as Diamond-Blackfan anemia (Perez-Losada et al., 2002), however more research is necessary to explore the involvement of Slug in this disease.

\subsection{Snail and Smuc in normal hematopoiesis}

Mice deficient for Snail are embryonic lethal at E7.5-8.5 due to defects in mesoderm formation (Carver et al., 2001) as well as vascular defects (Lomeli et al., 2009). Consequently, due to the early embryonic lethality, the effects of Snail loss on hematopoiesis could not be further investigated in these mice. Although some evidence exists that Snail is expressed in the hematopoietic system, more detailed research is necessary and final proof of its potential role in hematpoiesis will come from breeding the conditional floxed Snail mice (Murray S.A. et al., 2006) to mice with hematopoietic-specific transgenic Cre lines.

Based upon the fact that in vitro Snail binds similar E-box binding domains and in general shows more drastic phenotypes both in vitro as in vivo compared to Slug, Snail may also play crucial roles in hematopoiesis. Interestingly, Snail and Slug in most cases can complement each other and differences in phenotypes can be explained by differences in expression patterns as exemplified by the aggravated phenotypes of the Snail/Slug double knockouts (Murray S.A. et al., 2007). In addition, loss of one Snai family member often induces or increases the expression of the other(s). In this way hematopoietic-specific double knockouts may reveal even more functions for Snail and Slug in normal hematopoiesis.

More recently a third family member of the Snail family was identified in vertebrates, Smuc. Until now, little is known about its functions but it is abundantly expressed in thymocytes (Zhuge et al., 2005), specifically in the early CD4-CD8- double negative (DN) and 
CD4+CD8+ double positive (DP) stages of thymocyte maturation and then solely expressed in the $\mathrm{CD}^{+} \mathrm{T}$ lymphocyte lineage both in the thymus and peripheral immune system. In macrophages, Smuc is able to interact with PU.1, a master regulator of myeloid differentiation, and binds the negative regulatory element within the Pactolus promoter. These data suggests that Smuc is modulating the PU.1 transcriptional activity and lack of Smuc leads to aberrant PU.1 transactivation (Hale et al., 2006).

\subsection{Overexpression of Snail or Slug induces leukemia}

Based on the prominent roles of Snail and Slug in stress-induced hematopoiesis, and their roles in the progression of solid tumours, as well as acquisition of cancer stem cell characteristics, it is therefore surprising that only a limited number of studies have addressed the roles of Snai family members in hematopoietic malignancies.

Nevertheless, strong evidence that Snail and Slug are involved in leukemia formation and/or progression comes from the gain-of-function mouse models that were previously developed. CombiTA-Snail mice, carrying a hypermorphic tetracycline-repressible Snail transgene, showed increased Snail expression up to $20 \%$ above normal levels (PerezMancera et al., 2005b). These mice survive and are fertile and although no morphological alterations were observed, their thymus were smaller and showed reduced differentiation towards CD4+CD8+ DP thymocytes. From 5-7 months onwards, CombiTA-Snail mice started to develop various types of epithelial and non-epithelial cancers especially lymphomas and acute leukemias (> 75\% in two separate transgenic lines). Suppression of the Snail transgene expression by tetracycline administration did not ameliorate the malignant phenotype, suggesting that the effect of Snail overexpression is irreversible. As well, CombiTA-Snail transgene expression resulted in increased in vivo radioprotection, suggesting similar roles for Snail in hematopoietic cell survival upon genotoxic stress as was previously shown for Slug.

Similar experiments were performed for in vivo overexpression of Slug. In a similar setup as described above for Snail, CombiTA-Slug mice were generated. To prove transgene functionality, these mice were crossed with Slug deficient mice, which rescued the null phenotype. Again these mice were born without overt morphological abnormalities (PerezMancera et al., 2006). Only after 6-8 months $20 \%$ of the transgenic mice died as a consequence of congestive heart failure. The surviving mice started to develop various tumors from 9 months of age with highest incidence of $(90 \%)$ acute leukemias (PerezMancera et al., 2005a). Similar as to the CombiTA-Snail mice this malignant phenotype was irreversible after tetracycline administration. As well, c-Kit signaling has been implicated both in solid tumors as well as leukemias, e.g. constitutive activating mutations of the receptor have been described in AML (Jung et al., 2011) Furthermore, the BCR-ABL oncogene did not induce leukaemia in Slug-deficient mice, implicating Slug in BCR-ABL leukemogenesis in vivo (Perez-Mancera et al., 2005a). As well, in an independent study it was shown that the increased Slug expression upon Bcr-Abl mutations is involved in the prolonged survival of chronic myeloid leukemia cells (Mancini et al., 2010).

From the Slug knockout mice it appears that it is governing a pivotal role in cell survival upon DNA damage by repressing the pro-apoptotic factor Puma. These results may be highly relevant for cancer therapy. Analyzing or controlling Slug levels before or during 
treatment may be useful as a prognostic marker for sensitivity to genotoxic agents and can be helpful for limiting therapeutic doses or increasing the efficiency of radiation or chemotherapy.

\section{EMT regulators of the Zeb family}

The Zinc finger E-Box binding (ZEB) family of DNA-binding transcriptional regulators consists of two structurally related proteins (Fortini et al., 1991)(Fig. 2): Zeb1 (also known as SEF-1, TCF8, BZP, ZEB, AREB6, NIL-2-A, Zfhep, and Zfhx1a) and Zeb2 (also known as Sip1, KIAA0569 and Zfhx1b). Both genes have a very similar genomic structures (Fortini et al., 1991; Vandewalle et al., 2009) and encode for large multi-domain proteins that possess Nterminal and C-terminal zinc finger DNA binding domains along with more centrally located homeo (HD), Smad protein binding (SBD) and CtBP interaction (CID) domains; and in the case of Zeb2, an N-terminal NuRD interaction domain (Verstappen et al., 2008). II

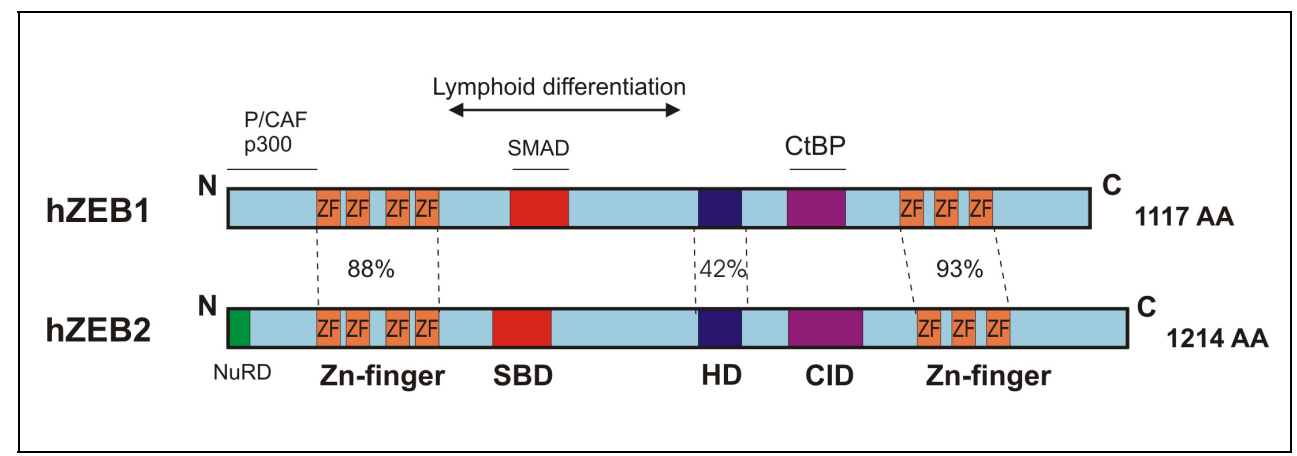

Fig. 2. Schematic diagram of conserved functional domains of the two members of the Zeb family of transcription factors. Both possess 2 zinc-finger domains, a homeodomain (HD), Smad (SBD) and CtBP (CID) binding domain (Figure based on Vandewalle et al., 2009)

Especially within the Zn-finger domains there exists a high degree of sequence similarity/identity between the two Zeb proteins, suggesting they bind similar target sequences (Verschueren et al., 1999). Each Zn-finger cluster independently can bind a 5'CACCT(G)-3' sequence located in the target promotor region (Remacle et al., 1999). The domains outside the $\mathrm{Zn}$-finger clusters seem less conserved and may be essential for the recruitment of various co-repressors, like CtBP (Grooteclaes \& Frisch, 2000;Postigo \& Dean, 1999b; van Grunsven et al., 2007) or co-activators like p300 or P/CAF (van Grunsven et al., 2006). Still a lot of controversy exists over whether Zeb proteins can only act as transcriptional repressors or as well as activators. The molecular mechanism underlying the choice between repression or activation are currently unknown and may include cell-type specific differences and/or posttranslational modifications (Costantino et al., 2002). Similarly, the roles of Zeb proteins in TGF $\beta$ /BMP signaling are not well understood; both Zebs have been shown to be able to bind receptor activated R-Smads (Postigo, 2003; Verschueren et al., 1999). Postigo et al. (Postigo, 2003) postulated Zeb proteins as putative important downstream mediators of this signaling pathway however with opposing effects. While Zeb1 would synergize with Smad proteins to activate transcription of TGF $\beta$ 
responsive reporter constructs, the structurally very similar Zeb2 would inhibit transcriptional activation donwstream of TGF $\beta$ (Postigo, 2003). These antagonistic effects were hypothesized to result from differential recruitment of co-activators and co-repressors to the Smads by Zeb1 or Zeb2 respectively (Postigo et al., 2003).

The Zeb family of zinc finger/homeodomain proteins genes was first idenfied in Drosphila melanogaster (Fortini et al., 1991) and shown to be essential for myogenesis (Postigo et al., 1999) and the organization of the central nervous system (Clark \& Chiu, 2003). As well in vertebrates a vast number of muscle master regulatory genes have been shown to be repressed directly by Zeb1/2 ( $\alpha 7$ integrin, $\delta$ crystalin enhancer, Mef2c) (Postigo \& Dean, 1997, 1999a) as well as genes essential for cartilage and bone formation (Col2 $\alpha 1)$ (Murray D. et al., 2000). The first functional studies in Xenopus proved Zeb1 to be essential for the expression of XBra (Xenopus Brachyury) (Papin et al., 2002), a member of T-box family of transcription factor essential for mesoderm formation and notochord differentiation and previously been implicated in EMT processes. Subsequently various in vitro studies using multiple epithelial cancer cell lines, it was demonstrated that both Zeb1/2 are able to bind and downregulate Ecadherin (Comijn et al., 2001; Eger et al., 2005) and other epithelial-specific marker genes via binding bipartite E-boxes in their promotor regions. Exogeneous Zeb1/2 overexpression results in EMT-like phenotypes similarly as described above for the Snai family members of EMT inducers (Comijn et al., 2001; Vandewalle et al., 2005). Increased in vivo Zeb1/2 expression has been correlated in various tumor types with increased invasion, metastasis, dedifferentiation, cancer stem cell characteristics, recurrence and bad prognosis (Spaderna et al., 2006; Spoelstra et al., 2006; Wellner et al., 2009; Yoshihara et al., 2009).

Besides their roles in suppression of epithelial marker genes more and more studies revealed their participation in other cellular processes like cell division (Mejlvang et al., 2007), apoptosis and senescence (Liu Y. et al., 2008; Ozturk et al., 2006; Sayan et al., 2009) and inflammation (Chua et al., 2007).

From expression analysis it was clear that both Zeb proteins are also expressed in the hematopoietic system. Actually, Zeb1 has been demonstrated to be more expressed during Tlymphocyte development, while Zeb2 expression has been seen more in splenic B cells (Postigo \& Dean, 2000). Using various novel mouse models recent data clearly indicated that this family of EMT inducers also plays pivotal roles in various steps of hematopoietic differentiation and progression of hematopoietic malignancies, which are discussed in detail below.

\subsection{Role of Zeb2 in hematopoietic stem/progenitor differentiation and mobilization}

Moderate to high Zeb2 expression is reported in all hematopoietic cells with highest levels in stem (HSC) and progenitor (HPC) populations (Goossens et al., 2011) and lowest expression in mature T cells (Postigo \& Dean, 2000). Through the use of a conditional Zeb2 knockout mouse (Higashi et al., 2002) model we could show that it is not essential for the initial formation of HSCs in the embryo but it is crucial for HSC differentiation and mobilization/homing (Goossens et al., 2011). Hematopoietic-specific Zeb2 loss-of-function resulted in embryonic lethality resulting from bleedings occurring in the developing brain. The observed phenotype is very reminiscent of the phenotypes associated with ubiquitous loss of the hematopoietic transcriptional regulators AML/Runx1 (Okuda et al., 1996). Runx1 knockout embryos are deficient in AGM HSCs and lack intra-arterial hematopoietic clusters, 
suggesting that Zeb2 deletion may also affect hematopoietic cluster formation. However, no changes in the number of hematopoietic progenitor clusters was detected for the Zeb2 null AGM regions (Goossens et al., 2011) indicating that the formed stem cells are not functional at later stages of development. Zeb2 seems to be more involved in stem/progenitor differentiation properties as isolated progenitors from various developing hematopoietic organs were unable to differentiate in vitro. As well, significant decreases in fully differentiated hematopoietic cells were observed. Next to this differentiation block, an increased adhesion/clustering of hematopoietic cells in the fetal liver and less mobile progenitors in the peripheral blood were observed. It was hypothesized that the increased levels of Cxcr4 within the Zeb2 null progenitors lead to their retention in the fetal liver that resulted in less progenitors in the embryonic circulation. This decreased mobilization of hematopoietic progenitors likely contributed to the decreased levels of angiogenic factors (like Ang1) within the circulation, thereby resulting in less maturation and pericyte recruitment towards the newly formed vessels in the developing brain. Most probably this defect contributed to the observed cephalic bleeding phenotype. From this initial data it has become clear that Zeb2 is not only a crucial transcriptional regulator of hematopoietic differentiation but as well plays pivotal roles in the mobilization and homing of HSCs within the embryo (Goossens et al., 2011). More experiments need to be performed to analyze whether this also holds true in adult haematopoiesis.

\subsection{Role of Zeb1 in T cell development}

Neonatal Zeb1 total knockout mice die shortly after birth. Drastic skeletal abnormalities (Takagi et al., 1998) and serious thymic atrophy were observed. Through the use of a second Zeb1 loss-of-function mouse model, expressing a C-terminal zinc finger truncation allowed survival to adulthood, it was feasible to further investigate the in vivo role of Zeb1 in adult hematopoiesis (Higashi et al., 1997). In these $\Delta$ C-fin mice no skeletal phenotypes were observed. On the other hand T lymphocyte differentiation was drastically impaired. This observation points towards the hypothesis that different domains of Zeb1 are responsible for alternative/synergistic functions, which as well was hypothesized previously by Postigo and colleagues via their in vitro approaches described above (Postigo \& Dean, 1999a). More detailed FACS analysis of Zeb1 $\Delta$ C-fin mutant thymocytes revealed a block at a very early stage in the cKit+ CD4-CD8-DN population, before rearrangements of the $\mathrm{T}$ cell receptor (TCR) locus (Higashi et al., 1997). Only a very small proportion of the intrathymic T cell precursors ( $<1 \%$ compared of the normal $\mathrm{T}$ cell development) was able to differentiate further and expressed differentiated $\mathrm{T}$ cell markers. These differentiated cells were skewed mainly towards CD4+CD8-SP cells, indicated that also at later stages of $\mathrm{T}$ cell development Zeb1 expression may play essential roles. More recently it was shown that Zeb1 binds the $5^{\prime}$ E-boxes in the proximal enhancer of the CD4 promoter and competes with the transcriptional activators E12 and HEB for DNA binding. Therefore it was concluded that overexpression of Zeb1 in T cells converts the CD4 proximal enhancer into a silencer element leading to a reduction of CD4 expression. This data shows that the CD4 gene is a direct target of the transcriptional repressor Zeb1 and can explain the increased proportion of CD4 ${ }^{+}$CD8-SP mature T cells in Zeb1 mutant mice (Brabletz et al., 1999).

Another known downstream target of Zeb1 during myogenesis is $\alpha 4$-integrin. Also in hematopoietic differentiation of various lineages $\alpha 4$-integrin is known to play crucial roles 
through its interaction with fibronectin and V-CAM in the stromal matrix and stromal cells of the bone marrow and fetal liver. $\alpha 4$-integrin is highly expressed in stem and progenitor cells and upon further differentiation its expression is restricted to lymphocytes and myeloid subpopulations. Zeb1 binds and directly represses $\alpha 4$-integrin expression (Postigo \& Dean, 1999a). Previously it was shown that $\alpha 4$ integrin expression depends on C-Myb and Ets family of transcription factors. Based on in vitro $\alpha 4$-intregrin promotor analysis, Postigo (Postigo \& Dean, 1997) concluded that Zeb1 blocks activity of c-Myb and Ets individually but together these synergize to overcome Zeb1 repression. Next to CD4 and $\alpha 4$ integrin, Zeb1 has been suggested to repress a number of other genes implicated in proper $\mathrm{T}$ cell differentiation like Gata3 (Gregoire \& Romeo, 1999), immunoglobin heavy chain enhancer (Genetta et al.,1994) and interleukin-2 (Williams T.M. et al., 1991; Yasui et al., 1998).

Within B-lymphocytes a functional cooperation between FoxO transcription factors and Zeb1 has been revealed. Zeb1 binds and activates two promotors of known FoxO target genes cyclin G2 and retinoblastoma-like 2. Both have been implicated in cell cycle arrest and Foxo-dependent quiescence in fibroblasts (Chen et al., 2006). However a role of Zeb1 in Bcell development has not been reported

\subsection{Role of Zeb1/2 in T and B cell acute lymphoblastic leukemia}

Using the same $\Delta \mathrm{C}$-fin Zeb1 mutant mice described above it was demonstrated that expression of the truncated Zeb1 protein resulted in the development of spontaneous CD4 ${ }^{+}$ T-cell lymphomas with a median onset at 30 weeks of age. This is consistent with the fact that ZEB1 expression is frequently lost in human adult T-cell leukemia/lymphoma (T-ALL) patients (Hidaka et al., 2008; Vermeer et al., 2008). In T-ALL cell lines it was demonstrated that the tumour cell's resistance to TGF- $\beta$ mediated growth suppression is via up-regulation of the inhibitory Smad7 (Nakahata et al., 2010). Here the role of Zeb proteins in the regulation of Smad7 remains needs to be better understood. Similarly the actual role of the other above described Zeb1 targets remains to be determined in T cell lymphomas.

The role of Zeb1 in B-Cell leukemia has not been reported. However, in terms of hematological malignancy, some independent genome-wide retroviral insertional mutagenesis screens have identified Zeb2 and not Zeb1 as a possible gene involved in mouse B-cell lymphoma progression (Lund et al., 2002; Mikkers et al., 2002; Shin et al., 2004). From these initial studies it was not clear if Zeb2 expression is lost due to retroviral integration and translocation events or enhanced during the transformation process. More recently in CALM-AF10 transgenic mice, enhanced Zeb2 expression was found to correlate with increased leukemia progression (Caudell et al., 2010). Additionally, knockdown of Zeb2 in a B-ALL cell line resulted in decreased proliferation rates. However in vivo Zeb2 overexpression studies are missing to be conclusive concerning the role of Zeb2 in leukemogenesis. Nevertheless, ZEB2 genomic locus rearrangements are commonly associated with aggressive B cell lymphomas in humans as well (Matteucci et al., 2008).

\section{Conclusions}

From the above literature survey it is clear that EMT inducers of the Snai and Zeb families play crucial and yet specific roles during various stages of hematopoiesis and leukemic transformation. These specific roles are in some way surprising given that they all bind 
similar E box-containing DNA sequences and a significant overlap in target genes has been reported. This can in some ways be explained by differences in their expression patterns and/or the recruitment of other cell-specific co-repressors and/or activators.

As well, the above reviewed data clearly indicate crucial roles for the EMT inducers of the Zeb and Snai family in different aspects of hematopoiesis: differentiation, proliferation, apoptosis/survival, mobilization, stemness, as well as quiescence. All of this suggests that these two family of proteins might be excellent targets for developing novel and improved cancer therapies not only as was suggested before for solid tumours but as well for bloodborne cancers and other haematological defects associated with improper lineage differentiation.

\section{Acknowledgment}

This work was partially supported by the European Hematology Association (EHA Young Investigator Fellowship 2009/26 to SG). SG is a postdoctoral fellow of the Basic Science Research Foundation-Flanders (FWO).

\section{References}

Al-Hajj, M., Wicha, M.S., Benito-Hernandez, A., Morrison, S.J. \& Clarke, M.F. (2003) Prospective identification of tumorigenic breast cancer cells. Proceedings of the National Academy of Sciences of the United States of America, Vol.100, No.7, pp. 39833988

Batlle, E., Sancho, E., Franci, C., Dominguez, D., Monfar, M., Baulida, J. \& Garcia De Herreros, A. (2000) The transcription factor snail is a repressor of e-cadherin gene expression in epithelial tumour cells. Nature cell biology, Vol.2, No.2, pp. 84-89

Berx, G., Raspe, E., Christofori, G., Thiery, J.P. \& Sleeman, J.P. (2007) Pre-emting metastasis? Recapitulation of morphogenetic processes in cancer. Clinical $\mathcal{E}$ experimental metastasis, Vol.24, No.8, pp. 587-597

Boisset, J.C., van Cappellen, W., Andrieu-Soler, C., Galjart, N., Dzierzak, E. \& Robin, C. In vivo imaging of haematopoietic cells emerging from the mouse aortic endothelium. Nature, Vol.464, No.7285, pp. 116-120

Bonnet, D. \& Dick, J.E. (1997) Human acute myeloid leukemia is organized as a hierarchy that originates from a primitive hematopoietic cell. Nature medicine, Vol.3, No.7, pp. 730-737

Boulay, J.L., Dennefeld, C. \& Alberga, A. (1987) The drosophila developmental gene snail encodes a protein with nucleic acid binding fingers. Nature, Vol.330, No.6146, pp. 395-398

Brabletz, T., Jung, A., Hlubek, F., Lohberg, C., Meiler, J., Suchy, U. \& Kirchner, T. (1999) Negative regulation of cd4 expression in $\mathrm{t}$ cells by the transcriptional repressor zeb. International immunology, Vol.11, No.10, pp. 1701-1708

Cano, A., Perez-Moreno, M.A., Rodrigo, I., Locascio, A., Blanco, M.J., del Barrio, M.G., Portillo, F. \& Nieto, M.A. (2000) The transcription factor snail controls epithelialmesenchymal transitions by repressing e-cadherin expression. Nature cell biology, Vol.2, No.2, pp. 76-83 
Carver, E.A., Jiang, R., Lan, Y., Oram, K.F. \& Gridley, T. (2001) The mouse snail gene encodes a key regulator of the epithelial-mesenchymal transition. Molecular and cellular biology, Vol.21, No.23, pp. 8184-8188

Caudell, D., Harper, D.P., Novak, R.L., Pierce, R.M., Slape, C., Wolff, L. \& Aplan, P.D. (2010) Retroviral insertional mutagenesis identifies zeb2 activation as a novel leukemogenic collaborating event in calm-af10 transgenic mice. Blood, Vol.115, No.6, pp. 1194-1203

Chabot, B., Stephenson, D.A., Chapman, V.M., Besmer, P. \& Bernstein, A. (1988) The protooncogene c-kit encoding a transmembrane tyrosine kinase receptor maps to the mouse w locus. Nature, Vol.335, No.6185, pp. 88-89

Chen, J., Yusuf, I., Andersen, H.M. \& Fruman, D.A. (2006) Foxo transcription factors cooperate with delta ef1 to activate growth suppressive genes in b lymphocytes. Journal of immunology, Vol.176, No.5, pp. 2711-2721

Chua, H.L., Bhat-Nakshatri, P., Clare, S.E., Morimiya, A., Badve, S. \& Nakshatri, H. (2007) Nf-kappab represses e-cadherin expression and enhances epithelial to mesenchymal transition of mammary epithelial cells: Potential involvement of zeb1 and zeb-2. Oncogene, Vol.26, No.5, pp. 711-724

Clark, S.G. \& Chiu, C. (2003) C. Elegans zag-1, a zn-finger-homeodomain protein, regulates axonal development and neuronal differentiation. Development, Vol.130, No.16, pp. 3781-3794

Cobaleda, C., Perez-Caro, M., Vicente-Duenas, C. \& Sanchez-Garcia, I. (2007) Function of the zinc-finger transcription factor snai2 in cancer and development. Annual review of genetics, Vol.41, pp. 41-61

Comijn, J., Berx, G., Vermassen, P., Verschueren, K., van Grunsven, L., Bruyneel, E., Mareel, M., Huylebroeck, D. \& van Roy, F. (2001) The two-handed e box binding zinc finger protein sip1 downregulates e-cadherin and induces invasion. Molecular Cell, Vol.7, No.6, pp. 1267-1278

Copeland, N.G., Gilbert, D.J., Cho, B.C., Donovan, P.J., Jenkins, N.A., Cosman, D., Anderson, D., Lyman, S.D. \& Williams, D.E. (1990) Mast cell growth factor maps near the steel locus on mouse chromosome 10 and is deleted in a number of steel alleles. Cell, Vol.63, No.1, pp. 175-183

Costantino, M.E., Stearman, R.P., Smith, G.E. \& Darling, D.S. (2002) Cell-specific phosphorylation of zfhep transcription factor. Biochemical and biophysical research communications, Vol.296, No.2, pp. 368-373

de Bruijn, M.F., Ma, X., Robin, C., Ottersbach, K., Sanchez, M.J. \& Dzierzak, E. (2002) Hematopoietic stem cells localize to the endothelial cell layer in the midgestation mouse aorta. Immunity, Vol.16, No.5, pp. 673-683

De Craene, B., van Roy, F. \& Berx, G. (2005) Unraveling signalling cascades for the snail family of transcription factors. Cellular signalling, Vol.17, No.5, pp. 535-547

del Barrio, M.G. \& Nieto, M.A. (2002) Overexpression of snail family members highlights their ability to promote chick neural crest formation. Development, Vol.129, No.7, pp. 1583-1593

Dzierzak, E. \& Medvinsky, A. (2008) The discovery of a source of adult hematopoietic cells in the embryo. Development, Vol.135, No.14, pp. 2343-2346

Dzierzak, E. \& Speck, N.A. (2008) Of lineage and legacy: The development of mammalian hematopoietic stem cells. Nature immunology, Vol.9, No.2, pp. 129-136 
Eger, A., Aigner, K., Sonderegger, S., Dampier, B., Oehler, S., Schreiber, M., Berx, G., Cano, A., Beug, H. \& Foisner, R. (2005) Deltaef1 is a transcriptional repressor of ecadherin and regulates epithelial plasticity in breast cancer cells. Oncogene, Vol.24, No.14, pp. 2375-2385

Fleming, W.H., Alpern, E.J., Uchida, N., Ikuta, K. \& Weissman, I.L. (1993) Steel factor influences the distribution and activity of murine hematopoietic stem cells in vivo. Proceedings of the National Academy of Sciences of the United States of America, Vol.90, No.8, pp. 3760-3764

Fortini, M.E., Lai, Z.C. \& Rubin, G.M. (1991) The drosophila zfh-1 and zfh-2 genes encode novel proteins containing both zinc-finger and homeodomain motifs. Mechanisms of development, Vol.34, No.2-3, pp. 113-122

Geissler, E.N., Ryan, M.A. \& Housman, D.E. (1988) The dominant-white spotting (w) locus of the mouse encodes the c-kit proto-oncogene. Cell, Vol.55, No.1, pp. 185-192

Genetta, T., Ruezinsky, D. \& Kadesch, T. (1994) Displacement of an e-box-binding repressor by basic helix-loop-helix proteins: Implications for b-cell specificity of the immunoglobulin heavy-chain enhancer. Molecular and cellular biology, Vol.14, No.9, pp. 6153-6163

Giebel, L.B. \& Spritz, R.A. (1991) Mutation of the kit (mast/stem cell growth factor receptor) protooncogene in human piebaldism. Proceedings of the National Academy of Sciences of the United States of America, Vol.88, No.19, pp. 8696-8699

Gill, J.G., Langer, E.M., Lindsley, R.C., Cai, M., Murphy, T.L. \& Murphy, K.M. (2011) Snail promotes the cell-autonomous generation of flk1+ endothelial cells through the repression of the mir-200 family. Stem cells and development, in press.

Goossens, S., Janzen, V., Bartunkova, S., Yokomizo, T., Drogat, B., Crisan, M., Haigh, K., Seuntjens, E., Umans, L., Riedt, T., Bogaert, P., Haenebalcke, L., Berx, G., Dzierzak, E., Huylebroeck, D. \& Haigh, J.J. (2011) The emt regulator zeb2/sip1 is essential for murine embryonic hematopoietic stem/progenitor cell differentiation and mobilization. Blood, Vol.117, No.21, pp. 5620-5630

Grau, Y., Carteret, C. \& Simpson, P. (1984) Mutations and chromosomal rearrangements affecting the expression of snail, a gene involved in embryonic patterning in drosophila melanogaster. Genetics, Vol.108, No.2, pp. 347-360

Greenburg, G. \& Hay, E.D. (1982) Epithelia suspended in collagen gels can lose polarity and express characteristics of migrating mesenchymal cells. The Journal of cell biology, Vol.95, No.1, pp. 333-339

Gregoire, J.M. \& Romeo, P.H. (1999) T-cell expression of the human gata-3 gene is regulated by a non-lineage-specific silencer. The Journal of biological chemistry, Vol.274, No.10, pp. 6567-6578

Grimes, H.L., Chan, T.O., Zweidler-McKay, P.A., Tong, B. \& Tsichlis, P.N. (1996) The gfi-1 proto-oncoprotein contains a novel transcriptional repressor domain, snag, and inhibits g1 arrest induced by interleukin-2 withdrawal. Molecular and cellular biology, Vol.16, No.11, pp. 6263-6272

Grooteclaes, M.L. \& Frisch, S.M. (2000) Evidence for a function of ctbp in epithelial gene regulation and anoikis. Oncogene, Vol.19, No.33, pp. 3823-3828

Gupta, P.B., Chaffer, C.L. \& Weinberg, R.A. (2009) Cancer stem cells: Mirage or reality? Nature medicine, Vol.15, No.9, pp. 1010-1012 
Hale, J.S., Dahlem, T.J., Margraf, R.L., Debnath, I., Weis, J.J. \& Weis, J.H. (2006) Transcriptional control of pactolus: Evidence of a negative control region and comparison with its evolutionary paralogue, cd18 (beta2 integrin). Journal of leukocyte biology, Vol.80, No.2, pp. 383-398

Hidaka, T., Nakahata, S., Hatakeyama, K., Hamasaki, M., Yamashita, K., Kohno, T., Arai, Y., Taki, T., Nishida, K., Okayama, A., Asada, Y., Yamaguchi, R., Tsubouchi, H., Yokota, J., Taniwaki, M., Higashi, Y. \& Morishita, K. (2008) Down-regulation of tcf8 is involved in the leukemogenesis of adult t-cell leukemia/lymphoma. Blood, Vol.112, No.2, pp. 383-393

Higashi, Y., Moribe, H., Takagi, T., Sekido, R., Kawakami, K., Kikutani, H. \& Kondoh, H. (1997) Impairment of $\mathrm{t}$ cell development in deltaef1 mutant mice. The Journal of experimental medicine, Vol.185, No.8, pp. 1467-1479

Higashi, Y., Maruhashi, M., Nelles, L., Van de Putte, T., Verschueren, K., Miyoshi, T., Yoshimoto, A., Kondoh, H. \& Huylebroeck, D. (2002) Generation of the floxed allele of the sip1 (smad-interacting protein 1) gene for cre-mediated conditional knockout in the mouse. Genesis, Vol.32, No.2, pp. 82-84

Huang, E., Nocka, K., Beier, D.R., Chu, T.Y., Buck, J., Lahm, H.W., Wellner, D., Leder, P. \& Besmer, P. (1990) The hematopoietic growth factor $\mathrm{kl}$ is encoded by the sl locus and is the ligand of the c-kit receptor, the gene product of the w locus. Cell, Vol.63, No.1, pp. 225-233

Inoue, A., Seidel, M.G., Wu, W., Kamizono, S., Ferrando, A.A., Bronson, R.T., Iwasaki, H., Akashi, K., Morimoto, A., Hitzler, J.K., Pestina, T.I., Jackson, C.W., Tanaka, R., Chong, M.J., McKinnon, P.J., Inukai, T., Grosveld, G.C. \& Look, A.T. (2002) Slug, a highly conserved zinc finger transcriptional repressor, protects hematopoietic progenitor cells from radiation-induced apoptosis in vivo. Cancer cell, Vol.2, No.4, pp. $279-288$

Inukai, T., Inoue, A., Kurosawa, H., Goi, K., Shinjyo, T., Ozawa, K., Mao, M., Inaba, T. \& Look, A.T. (1999) Slug, a ces-1-related zinc finger transcription factor gene with antiapoptotic activity, is a downstream target of the e2a-hlf oncoprotein. Molecular Cell, Vol.4, No.3, pp. 343-352

Jung, C.L., Kim, H.J., Kim, D.H., Huh, H., Song, M.J. \& Kim, S.H. (2011) Ckit mutation in therapy-related acute myeloid leukemia with mllt3/mll chimeric transcript from $\mathrm{t}(9 ; 11)(\mathrm{p} 22 ; \mathrm{q} 23)$. Annals of clinical and laboratory science, Vol.41, No.2, pp. 193-196

Kajita, M., McClinic, K.N. \& Wade, P.A. (2004) Aberrant expression of the transcription factors snail and slug alters the response to genotoxic stress. Molecular and cellular biology, Vol.24, No.17, pp. 7559-7566

Kalluri, R. (2009) Emt: When epithelial cells decide to become mesenchymal-like cells. The Journal of clinical investigation, Vol.119, No.6, pp. 1417-1419

Kalluri, R. \& Weinberg, R.A. (2009) The basics of epithelial-mesenchymal transition. The Journal of clinical investigation, Vol.119, No.6, pp. 1420-1428

Knight, R.D. \& Shimeld, S.M. (2001) Identification of conserved c2h2 zinc-finger gene families in the bilateria. Genome biology, Vol.2, No.5, pp. RESEARCH0016

Kondo, M., Wagers, A.J., Manz, M.G., Prohaska, S.S., Scherer, D.C., Beilhack, G.F., Shizuru, J.A. \& Weissman, I.L. (2003) Biology of hematopoietic stem cells and progenitors: Implications for clinical application. Annual review of immunology, Vol.21, pp. 759806 
LaBonne, C. \& Bronner-Fraser, M. (2000) Snail-related transcriptional repressors are required in xenopus for both the induction of the neural crest and its subsequent migration. Developmental biology, Vol.221, No.1, pp. 195-205

Li, R., Liang, J., Ni, S., Zhou, T., Qing, X., Li, H., He, W., Chen, J., Li, F., Zhuang, Q., Qin, B., Xu, J., Li, W., Yang, J., Gan, Y., Qin, D., Feng, S., Song, H., Yang, D., Zhang, B., Zeng, L., Lai, L., Esteban, M.A. \& Pei, D. (2010) A mesenchymal-to-epithelial transition initiates and is required for the nuclear reprogramming of mouse fibroblasts. Cell stem cell, Vol.7, No.1, pp. 51-63

Lin, Y., Wu, Y., Li, J., Dong, C., Ye, X., Chi, Y.I., Evers, B.M. \& Zhou, B.P. (2010) The snag domain of snail1 functions as a molecular hook for recruiting lysine-specific demethylase 1. The EMBO journal, Vol.29, No.11, pp. 1803-1816

Liu, J., Uygur, B., Zhang, Z., Shao, L., Romero, D., Vary, C., Ding, Q. \& Wu, W.S. (2010) Slug inhibits proliferation of human prostate cancer cells via downregulation of cyclin d1 expression. The Prostate, Vol.70, No.16, pp. 1768-1777

Liu, Y., El-Naggar, S., Darling, D.S., Higashi, Y. \& Dean, D.C. (2008) Zeb1 links epithelialmesenchymal transition and cellular senescence. Development, Vol.135, No.3, pp. 579-588

Lomeli, H., Starling, C. \& Gridley, T. (2009) Epiblast-specific snai1 deletion results in embryonic lethality due to multiple vascular defects. BMC research notes, Vol.2, pp. 22

Lund, A.H., Turner, G., Trubetskoy, A., Verhoeven, E., Wientjens, E., Hulsman, D., Russell, R., DePinho, R.A., Lenz, J. \& van Lohuizen, M. (2002) Genome-wide retroviral insertional tagging of genes involved in cancer in cdkn2a-deficient mice. Nature genetics, Vol.32, No.1, pp. 160-165

Lyons, J.G., Patel, V., Roue, N.C., Fok, S.Y., Soon, L.L., Halliday, G.M. \& Gutkind, J.S. (2008) Snail up-regulates proinflammatory mediators and inhibits differentiation in oral keratinocytes. Cancer research, Vol.68, No.12, pp. 4525-4530

Mancini, M., Petta, S., Iacobucci, I., Salvestrini, V., Barbieri, E. \& Santucci, M.A. (2010) Zincfinger transcription factor slug contributes to the survival advantage of chronic myeloid leukemia cells. Cellular signalling, Vol.22, No.8, pp. 1247-1253

Mani, S.A., Guo, W., Liao, M.J., Eaton, E.N., Ayyanan, A., Zhou, A.Y., Brooks, M., Reinhard, F., Zhang, C.C., Shipitsin, M., Campbell, L.L., Polyak, K., Brisken, C., Yang, J. \& Weinberg, R.A. (2008) The epithelial-mesenchymal transition generates cells with properties of stem cells. Cell, Vol.133, No.4, pp. 704-715

Manzanares, M., Locascio, A. \& Nieto, M.A. (2001) The increasing complexity of the snail gene superfamily in metazoan evolution. Trends in genetics, Vol.17, No.4, pp. 178181

Matteucci, C., Bracci, M., Barba, G., Carbonari, M., Casato, M., Visentini, M., Pulsoni, A., Varasano, E., Roti, G., La Starza, R., Crescenzi, B., Martelli, M.F., Fiorilli, M. \& Mecucci, C. (2008) Different genomic imbalances in low- and high-grade hcvrelated lymphomas. Leukemia, Vol.22, No.1, pp. 219-222

Mauhin, V., Lutz, Y., Dennefeld, C. \& Alberga, A. (1993) Definition of the DNA-binding site repertoire for the drosophila transcription factor snail. Nucleic acids research, Vol.21, No.17, pp. 3951-3957

Mejlvang, J., Kriajevska, M., Vandewalle, C., Chernova, T., Sayan, A.E., Berx, G., Mellon, J.K. \& Tulchinsky, E. (2007) Direct repression of cyclin d1 by sip1 attenuates cell cycle 
progression in cells undergoing an epithelial mesenchymal transition. Molecular biology of the cell, Vol.18, No.11, pp. 4615-4624

Migliaccio, G., Migliaccio, A.R., Valinsky, J., Langley, K., Zsebo, K., Visser, J.W. \& Adamson, J.W. (1991) Stem cell factor induces proliferation and differentiation of highly enriched murine hematopoietic cells. Proceedings of the National Academy of Sciences of the United States of America, Vol.88, No.16, pp. 7420-7424

Mikkers, H., Allen, J., Knipscheer, P., Romeijn, L., Hart, A., Vink, E. \& Berns, A. (2002) Highthroughput retroviral tagging to identify components of specific signaling pathways in cancer. Nature genetics, Vol.32, No.1, pp. 153-159

Miranda-Saavedra, D. \& Gottgens, B. (2008) Transcriptional regulatory networks in haematopoiesis. Current opinion in genetics $\mathcal{E}$ development, Vol.18, No.6, pp. 530-535

Murray, D., Precht, P., Balakir, R. \& Horton, W.E., Jr. (2000) The transcription factor deltaef1 is inversely expressed with type ii collagen mrna and can repress col2a1 promoter activity in transfected chondrocytes. The Journal of biological chemistry, Vol.275, No.5, pp. 3610-3618

Murray, S.A., Carver, E.A. \& Gridley, T. (2006) Generation of a snail1 (snai1) conditional null allele. Genesis, Vol.44, No.1, pp. 7-11

Murray, S.A., Oram, K.F. \& Gridley, T. (2007) Multiple functions of snail family genes during palate development in mice. Development, Vol.134, No.9, pp. 1789-1797

Nakahata, S., Yamazaki, S., Nakauchi, H. \& Morishita, K. (2010) Downregulation of zeb1 and overexpression of smad7 contribute to resistance to tgf-beta1-mediated growth suppression in adult t-cell leukemia/lymphoma. Oncogene, Vol.29, No.29, pp. 41574169

Nieto, M.A. (2002) The snail superfamily of zinc-finger transcription factors. Nature reviews, Vol.3, No.3, pp. 155-166

Nishikawa, S., Kusakabe, M., Yoshinaga, K., Ogawa, M., Hayashi, S., Kunisada, T., Era, T., Sakakura, T. \& Nishikawa, S. (1991) In utero manipulation of coat color formation by a monoclonal anti-c-kit antibody: Two distinct waves of c-kit-dependency during melanocyte development. The EMBO journal, Vol.10, No.8, pp. 2111-2118

Okuda, T., van Deursen, J., Hiebert, S.W., Grosveld, G. \& Downing, J.R. (1996) Aml1, the target of multiple chromosomal translocations in human leukemia, is essential for normal fetal liver hematopoiesis. Cell, Vol.84, No.2, pp. 321-330

Orkin, S.H. (2000) Diversification of haematopoietic stem cells to specific lineages. Nature reviews, Vol.1, No.1, pp. 57-64

Orkin, S.H. \& Zon, L.I. (2008) Hematopoiesis: An evolving paradigm for stem cell biology. Cell, Vol.132, No.4, pp. 631-644

Ozturk, N., Erdal, E., Mumcuoglu, M., Akcali, K.C., Yalcin, O., Senturk, S., Arslan-Ergul, A., Gur, B., Yulug, I., Cetin-Atalay, R., Yakicier, C., Yagci, T., Tez, M. \& Ozturk, M. (2006) Reprogramming of replicative senescence in hepatocellular carcinomaderived cells. Proceedings of the National Academy of Sciences of the United States of America, Vol.103, No.7, pp. 2178-2183

Palis, J., Chan, R.J., Koniski, A., Patel, R., Starr, M. \& Yoder, M.C. (2001) Spatial and temporal emergence of high proliferative potential hematopoietic precursors during murine embryogenesis. Proceedings of the National Academy of Sciences of the United States of America, Vol.98, No.8, pp. 4528-4533 
Papin, C., van Grunsven, L.A., Verschueren, K., Huylebroeck, D. \& Smith, J.C. (2002) Dynamic regulation of brachyury expression in the amphibian embryo by xsip1. Mechanisms of development, Vol.111, No.1-2, pp. 37-46

Perez-Losada, J., Sanchez-Martin, M., Rodriguez-Garcia, A., Sanchez, M.L., Orfao, A., Flores, T. \& Sanchez-Garcia, I. (2002) Zinc-finger transcription factor slug contributes to the function of the stem cell factor c-kit signaling pathway. Blood, Vol.100, No.4, pp. 1274-1286

Perez-Losada, J., Sanchez-Martin, M., Perez-Caro, M., Perez-Mancera, P.A. \& SanchezGarcia, I. (2003) The radioresistance biological function of the scf/kit signaling pathway is mediated by the zinc-finger transcription factor slug. Oncogene, Vol.22, No.27, pp. 4205-4211

Perez-Mancera, P.A., Gonzalez-Herrero, I., Perez-Caro, M., Gutierrez-Cianca, N., Flores, T., Gutierrez-Adan, A., Pintado, B., Sanchez-Martin, M. \& Sanchez-Garcia, I. (2005a) Slug in cancer development. Oncogene, Vol.24, No.19, pp. 3073-3082

Perez-Mancera, P.A., Perez-Caro, M., Gonzalez-Herrero, I., Flores, T., Orfao, A., de Herreros, A.G., Gutierrez-Adan, A., Pintado, B., Sagrera, A., Sanchez-Martin, M. \& SanchezGarcia, I. (2005b) Cancer development induced by graded expression of snail in mice. Human Molecular Genetics, Vol.14, No.22, pp. 3449-3461

Perez-Mancera, P.A., Gonzalez-Herrero, I., Maclean, K., Turner, A.M., Yip, M.Y., SanchezMartin, M., Garcia, J.L., Robledo, C., Flores, T., Gutierrez-Adan, A., Pintado, B. \& Sanchez-Garcia, I. (2006) Slug (snai2) overexpression in embryonic development. Cytogenetic and Genome Research, Vol.114, No.1, pp. 24-29

Postigo, A.A. \& Dean, D.C. (1997) Zeb, a vertebrate homolog of drosophila zfh-1, is a negative regulator of muscle differentiation. The EMBO journal, Vol.16, No.13, pp. 3935-3943

Postigo, A.A. \& Dean, D.C. (1999a) Independent repressor domains in zeb regulate muscle and t-cell differentiation. Molecular and cellular biology, Vol.19, No.12, pp. 7961-7971

Postigo, A.A. \& Dean, D.C. (1999b) Zeb represses transcription through interaction with the corepressor ctbp. Proceedings of the National Academy of Sciences of the United States of America, Vol.96, No.12, pp. 6683-6688

Postigo, A.A., Ward, E., Skeath, J.B. \& Dean, D.C. (1999) Zfh-1, the drosophila homologue of zeb, is a transcriptional repressor that regulates somatic myogenesis. Molecular and cellular biology, Vol.19, No.10, pp. 7255-7263

Postigo, A.A. \& Dean, D.C. (2000) Differential expression and function of members of the zfh-1 family of zinc finger/homeodomain repressors. Proceedings of the National Academy of Sciences of the United States of America, Vol.97, No.12, pp. 6391-6396

Postigo, A.A. (2003) Opposing functions of zeb proteins in the regulation of the tgfbeta/bmp signaling pathway. The EMBO journal, Vol.22, No.10, pp. 2443-2452

Postigo, A.A., Depp, J.L., Taylor, J.J. \& Kroll, K.L. (2003) Regulation of smad signaling through a differential recruitment of coactivators and corepressors by zeb proteins. The EMBO journal, Vol.22, No.10, pp. 2453-2462

Redmer, T., Diecke, S., Grigoryan, T., Quiroga-Negreira, A., Birchmeier, W. \& Besser, D. (2011) E-cadherin is crucial for embryonic stem cell pluripotency and can replace oct4 during somatic cell reprogramming. EMBO reports, Vol.12, No.7, pp. 720-726

Remacle, J.E., Kraft, H., Lerchner, W., Wuytens, G., Collart, C., Verschueren, K., Smith, J.C. \& Huylebroeck, D. (1999) New mode of DNA binding of multi-zinc finger 
transcription factors: Deltaef1 family members bind with two hands to two target sites. The EMBO journal, Vol.18, No.18, pp. 5073-5084

Ricci-Vitiani, L., Lombardi, D.G., Pilozzi, E., Biffoni, M., Todaro, M., Peschle, C. \& De Maria, R. (2007) Identification and expansion of human colon-cancer-initiating cells. Nature, Vol.445, No.7123, pp. 111-115

Robin, C., Ottersbach, K., Boisset, J.C., Oziemlak, A. \& Dzierzak, E. (2011) Cd41 is developmentally regulated and differentially expressed on mouse hematopoietic stem cells. Blood, Vol.117, No.19, pp. 5088-5091

Rybtsov, S., Sobiesiak, M., Taoudi, S., Souilhol, C., Senserrich, J., Liakhovitskaia, A., Ivanovs, A., Frampton, J., Zhao, S. \& Medvinsky, A. (2011) Hierarchical organization and early hematopoietic specification of the developing hsc lineage in the agm region. The Journal of experimental medicine, Vol.208, No.6, pp. 1305-1315

Sanchez-Martin, M., Perez-Losada, J., Rodriguez-Garcia, A., Gonzalez-Sanchez, B., Korf, B.R., Kuster, W., Moss, C., Spritz, R.A. \& Sanchez-Garcia, I. (2003) Deletion of the slug (snai2) gene results in human piebaldism. American journal of medical genetics, Vol.122A, No.2, pp. 125-132

Sayan, A.E., Griffiths, T.R., Pal, R., Browne, G.J., Ruddick, A., Yagci, T., Edwards, R., Mayer, N.J., Qazi, H., Goyal, S., Fernandez, S., Straatman, K., Jones, G.D., Bowman, K.J., Colquhoun, A., Mellon, J.K., Kriajevska, M. \& Tulchinsky, E. (2009) Sip1 protein protects cells from DNA damage-induced apoptosis and has independent prognostic value in bladder cancer. Proceedings of the National Academy of Sciences of the United States of America, Vol.106, No.35, pp. 14884-14889

Schatton, T., Frank, N.Y. \& Frank, M.H. (2009) Identification and targeting of cancer stem cells. BioEssays, Vol.31, No.10, pp. 1038-1049

Sefton, M., Sanchez, S. \& Nieto, M.A. (1998) Conserved and divergent roles for members of the snail family of transcription factors in the chick and mouse embryo. Development, Vol.125, No.16, pp. 3111-3121

Shin, M.S., Fredrickson, T.N., Hartley, J.W., Suzuki, T., Akagi, K. \& Morse, H.C., 3rd (2004) High-throughput retroviral tagging for identification of genes involved in initiation and progression of mouse splenic marginal zone lymphomas. Cancer research, Vol.64, No.13, pp. 4419-4427

Singh, S.K., Clarke, I.D., Hide, T. \& Dirks, P.B. (2004) Cancer stem cells in nervous system tumors. Oncogene, Vol.23, No.43, pp. 7267-7273

Spaderna, S., Schmalhofer, O., Hlubek, F., Berx, G., Eger, A., Merkel, S., Jung, A., Kirchner, T. \& Brabletz, T. (2006) A transient, emt-linked loss of basement membranes indicates metastasis and poor survival in colorectal cancer. Gastroenterology, Vol.131, No.3, pp. 830-840

Spoelstra, N.S., Manning, N.G., Higashi, Y., Darling, D., Singh, M., Shroyer, K.R., Broaddus, R.R., Horwitz, K.B. \& Richer, J.K. (2006) The transcription factor zeb1 is aberrantly expressed in aggressive uterine cancers. Cancer research, Vol.66, No.7, pp. 3893-3902

Sun, Y., Shao, L., Bai, H., Wang, Z.Z. \& Wu, W.S. (2010) Slug deficiency enhances selfrenewal of hematopoietic stem cells during hematopoietic regeneration. Blood, Vol.115, No.9, pp. 1709-1717

Takagi, T., Moribe, H., Kondoh, H. \& Higashi, Y. (1998) Deltaef1, a zinc finger and homeodomain transcription factor, is required for skeleton patterning in multiple lineages. Development, Vol.125, No.1, pp. 21-31 
Thiery, J.P. \& Sleeman, J.P. (2006) Complex networks orchestrate epithelial-mesenchymal transitions. Nature reviews, Vol.7, No.2, pp. 131-142

Thiery, J.P., Acloque, H., Huang, R.Y. \& Nieto, M.A. (2009) Epithelial-mesenchymal transitions in development and disease. Cell, Vol.139, No.5, pp. 871-890

van Grunsven, L.A., Taelman, V., Michiels, C., Opdecamp, K., Huylebroeck, D. \& Bellefroid, E.J. (2006) Deltaef1 and sip1 are differentially expressed and have overlapping activities during xenopus embryogenesis. Developmental dynamics, Vol.235, No.6, pp. 1491-1500

van Grunsven, L.A., Taelman, V., Michiels, C., Verstappen, G., Souopgui, J., Nichane, M., Moens, E., Opdecamp, K., Vanhomwegen, J., Kricha, S., Huylebroeck, D. \& Bellefroid, E.J. (2007) Xsip1 neuralizing activity involves the co-repressor ctbp and occurs through bmp dependent and independent mechanisms. Developmental biology, Vol.306, No.1, pp. 34-49

Vandewalle, C., Comijn, J., De Craene, B., Vermassen, P., Bruyneel, E., Andersen, H., Tulchinsky, E., Van Roy, F. \& Berx, G. (2005) Sip1/zeb2 induces emt by repressing genes of different epithelial cell-cell junctions. Nucleic acids research, Vol.33, No.20, pp. 6566-6578

Vandewalle, C., Van Roy, F. \& Berx, G. (2009) The role of the zeb family of transcription factors in development and disease. Cellular and molecular life sciences, Vol.66, No.5, pp. 773-787

Vermeer, M.H., van Doorn, R., Dijkman, R., Mao, X., Whittaker, S., van Voorst Vader, P.C., Gerritsen, M.J., Geerts, M.L., Gellrich, S., Soderberg, O., Leuchowius, K.J., Landegren, U., Out-Luiting, J.J., Knijnenburg, J., Ijszenga, M., Szuhai, K., Willemze, R. \& Tensen, C.P. (2008) Novel and highly recurrent chromosomal alterations in sezary syndrome. Cancer research, Vol.68, No.8, pp. 2689-2698

Verschueren, K., Remacle, J.E., Collart, C., Kraft, H., Baker, B.S., Tylzanowski, P., Nelles, L., Wuytens, G., Su, M.T., Bodmer, R., Smith, J.C. \& Huylebroeck, D. (1999) Sip1, a novel zinc finger/homeodomain repressor, interacts with smad proteins and binds to 5 '-cacct sequences in candidate target genes. The Journal of biological chemistry, Vol.274, No.29, pp. 20489-20498

Verstappen, G., van Grunsven, L.A., Michiels, C., Van de Putte, T., Souopgui, J., Van Damme, J., Bellefroid, E., Vandekerckhove, J. \& Huylebroeck, D. (2008) Atypical mowat-wilson patient confirms the importance of the novel association between zfhx1b/sip1 and nurd corepressor complex. Human Molecular Genetics, Vol.17, No.8, pp. 1175-1183

Wang, Y., Mah, N., Prigione, A., Wolfrum, K., Andrade-Navarro, M.A. \& Adjaye, J. (2010) A transcriptional roadmap to the induction of pluripotency in somatic cells. Stem cell reviews, Vol.6, No.2, pp. 282-296

Wellner, U., Schubert, J., Burk, U.C., Schmalhofer, O., Zhu, F., Sonntag, A., Waldvogel, B., Vannier, C., Darling, D., zur Hausen, A., Brunton, V.G., Morton, J., Sansom, O., Schuler, J., Stemmler, M.P., Herzberger, C., Hopt, U., Keck, T., Brabletz, S. \& Brabletz, T. (2009) The emt-activator zeb1 promotes tumorigenicity by repressing stemness-inhibiting micrornas. Nature cell biology, Vol.11, No.12, pp. 1487-1495

Williams, N., Bertoncello, I., Kavnoudias, H., Zsebo, K. \& McNiece, I. (1992) Recombinant rat stem cell factor stimulates the amplification and differentiation of fractionated mouse stem cell populations. Blood, Vol.79, No.1, pp. 58-64 
Williams, T.M., Moolten, D., Burlein, J., Romano, J., Bhaerman, R., Godillot, A., Mellon, M., Rauscher, F.J., 3rd \& Kant, J.A. (1991) Identification of a zinc finger protein that inhibits il-2 gene expression. Science, Vol.254, No.5039, pp. 1791-1794

Wu, W.S., Heinrichs, S., Xu, D., Garrison, S.P., Zambetti, G.P., Adams, J.M. \& Look, A.T. (2005) Slug antagonizes p53-mediated apoptosis of hematopoietic progenitors by repressing puma. Cell, Vol.123, No.4, pp. 641-653

Wu, Y. \& Zhou, B.P. (2010) Snail: More than emt. Cell adhesion \& migration, Vol.4, No.2, pp. 199-203

Yang, C.C. \& Wolf, D.A. (2009) Inflamed snail speeds metastasis. Cancer cell, Vol.15, No.5, pp. 355-357

Yasui, D.H., Genetta, T., Kadesch, T., Williams, T.M., Swain, S.L., Tsui, L.V. \& Huber, B.T. (1998) Transcriptional repression of the il-2 gene in th cells by zeb. Journal of immunology, Vol.160, No.9, pp. 4433-4440

Yokomizo, T., Ng, C.E., Osato, M. \& Dzierzak, E. (2011) Three-dimensional imaging of whole midgestation murine embryos shows an intravascular localization for all hematopoietic clusters. Blood, Vol.117, No.23, pp. 6132-6134

Yoshihara, K., Tajima, A., Komata, D., Yamamoto, T., Kodama, S., Fujiwara, H., Suzuki, M., Onishi, Y., Hatae, M., Sueyoshi, K., Fujiwara, H., Kudo, Y., Inoue, I. \& Tanaka, K. (2009) Gene expression profiling of advanced-stage serous ovarian cancers distinguishes novel subclasses and implicates zeb2 in tumor progression and prognosis. Cancer science, Vol.100, No.8, pp. 1421-1428

Zhuge, X., Kataoka, H., Tanaka, M., Murayama, T., Kawamoto, T., Sano, H., Togi, K., Yamauchi, R., Ueda, Y., Xu, Y., Nishikawa, S., Kita, T. \& Yokode, M. (2005) Expression of the novel snai-related zinc-finger transcription factor gene smuc during mouse development. International journal of molecular medicine, Vol.15, No.6, pp. $945-948$

Zovein, A.C., Turlo, K.A., Ponec, R.M., Lynch, M.R., Chen, K.C., Hofmann, J.J., Cox, T.C., Gasson, J.C. \& Iruela-Arispe, M.L. (2010) Vascular remodeling of the vitelline artery initiates extravascular emergence of hematopoietic clusters. Blood, Vol.116, No.18, pp. 3435-3444

Zsebo, K.M., Williams, D.A., Geissler, E.N., Broudy, V.C., Martin, F.H., Atkins, H.L., Hsu, R.Y., Birkett, N.C., Okino, K.H., Murdock, D.C. \& et al. (1990) Stem cell factor is encoded at the sl locus of the mouse and is the ligand for the c-kit tyrosine kinase receptor. Cell, Vol.63, No.1, pp. 213-224 